Research Paper

\title{
Anti-inflammation and Anti-Cancer Activity of Ethanol Extract of Antarctic Freshwater Microalga, Micractinium
}

sp.

Sung-Suk Suh ${ }^{\circledR}$, Ju-Mi Hong ${ }^{2}$, Eun Jae Kim², 4, Seung Won Jung 3 , Sun-Mi Kim², Jung Eun Kim², 4, Il-Chan $\mathrm{Kim}^{2,4}$ and Sanghee Kim², 4

1. Department of Bioscience, Mokpo National University, Muan 58554, Republic of Korea

2. Department of Polar Life Sciences, Korea Polar Research Institute, Incheon 21990, Republic of Korea

3. South Sea Environment Research Department, Korea Institute of Ocean Science and Technology, Geoje, 656-830, Republic of Korea

4. Department of Polar Sciences, University of Science and Technology, Incheon 21990, Republic of Korea

$\triangle$ Corresponding author: sangheekim@kopri.re.kr, Tel: 82-32-760-5515 Fax: 82-32-760-5509

(C) Ivyspring International Publisher. This is an open access article distributed under the terms of the Creative Commons Attribution (CC BY-NC) license (https://creativecommons.org/licenses/by-nc/4.0/). See http://ivyspring.com/terms for full terms and conditions.

Received: 2018.04.01; Accepted: 2018.05.27; Published: 2018.06.12

\begin{abstract}
Inflammation mediated by the innate immune system is an organism's protective mechanism against infectious environmental risk factors. It is also a driver of the pathogeneses of various human diseases, including cancer development and progression. Microalgae are increasingly being focused on as sources of bioactive molecules with therapeutic potential against various diseases. Furthermore, the antioxidant, anti-inflammatory, and anticancer potentials of microalgae and their secondary metabolites have been widely reported. However, the underlying mechanisms remain to be elucidated. Therefore, in this study, we investigated the molecular mechanisms underlying the anti-inflammatory and anticancer activities of the ethanol extract of the Antarctic freshwater microalga Micractinium sp. (ETMI) by several in vitro assays using RAW 264.7 macrophages and HCT1 16 human colon cancer cells. ETMI exerted its anti-inflammatory activity by modulating the main inflammatory indicators such as cyclooxygenase (COX)-2, interleukin (IL)-6, inducible nitric oxide synthase (iNOS), tumor necrosis factor (TNF)- $\alpha$, and nitric oxide (NO) in a dose-dependent manner. In addition, ETMI exerted cytotoxic activity against HCT116 cells in a dose-dependent manner, leading to significantly reduced cancer cell proliferation. Further, it induced cell cycle arrest in the Gl phase through the regulation of hallmark genes of the GI/S phase transition, including $C D K N I A$, and cyclin-dependent kinase 4 and 6 (CDK4 and CDK6, respectively). At the transcriptional level, the expression of CDKNIA gradually increased in response to ETMI treatment while that of CDK4 and CDK6 decreased. Taken together, our findings suggest that the anti-inflammatory and anticancer activities of the Antarctic freshwater microalga, Micractinium sp., and ETMI may provide a new clue for understanding the molecular link between inflammation and cancer and that ETMI may be a potential anticancer agent for targeted therapy of colorectal cancer.
\end{abstract}

Key words: Inflammation, cancer, Micractinium sp., proinflammatory cytokines, HCT116

\section{Introduction}

Inflammation is a defense response mediated by the innate immune system to reinstate cellular homeostasis against foreign pathogenic agents that disrupt the integrity of cellular homeostasis [1-3]. The biological mechanisms underlying inflammatory processes, which comprise three distinct steps, initiation, regulation, and resolution, are tightly regulated to maintain physiological and cellular homeostasis inside the organism [4,5]. If the tissue is damaged due to a pathogenic infection, the cells of our body activate a signal pathway including cytokines and chemokines to cause an immune 
response. For example, macrophages, which are mainly located in the infected area, recognize the infection and secrete proinflammatory cytokines that attract other immune cells such as leukocytes and lymphocytes to the infected area, leading to inflammation. The recruited immune cells contribute to strengthening of the immune response against infection and the homeostatic state disrupted by infection is rapidly recovered into the normal state [6, 7]. If acute inflammation remains unresolved for any reason and progresses to chronic inflammation, which is the major driver of the pathogeneses of many diseases including cancer, the inflammatory cells are broken down and various inflammation inducers such as tumor necrosis factor (TNF)- $a$, interleukin-1 (IL)-1, and IL-6 are secreted, leading to DNA damage or mutations to form tumors [8-10]. In addition, inflammatory cells overexpress inflammatory cytokines or enzymes such as epidermal growth factor (EGF), matrix metalloproteinase (MMP), and monocyte chemo-attractant protein (MCP) [11]. These substances change the inflammatory microenvironment around the tumor, helping the tumor to proliferate and progress rapidly and thus making it easier for the tumor cells to break down nearby tissues and make the transition easier. To better understand the regulatory mechanisms underlying the progression of inflammation to cancer and development of inflammation-related cancers, it is necessary to determine the roles of the main regulatory molecules involved in the process, such as cytokines, nuclear factor (NF)-kB, cyclooxygenase (COX)-2, and inducible nitric oxide synthase (iNOS) [12, 13]. Cytokines produced in immune/inflammatory cells, including ILs and TNF- $\alpha$, play an important role in tumorigenesis through the modulation of transcription factors, such as NF- $\mathrm{kB}$, signal transducer and activator of transcription 3 (STAT3), and activator protein 1 (AP-1), to induce regulatory genes that promote cell proliferation and survival. Another key regulatory molecule in inflammation-mediated tumor development, NF- $\mathrm{kB}$, acts as a transcriptional factor to control the expression of many regulatory molecules in response to inflammation, such as IL-6, TNF-a, iNOS, COX-2, and chemokines [12-14]. In fact, NF-кB and its downstream target genes, iNOS and COX-2, are constitutively activated in various cancer types and play crucial roles in tumorigenesis by regulating cellular proliferation, antiapoptotic activity, and angiogenesis, and enhancing metastasis $[15,16]$.

Recently, microalgae have been increasingly highlighted as a source of bioactive molecules with pharmacological and therapeutic potential against inflammation and cancer. For example, the cytotoxicity of microalgal extracts and their secondary metabolites such as ramalin and lobaric acid has been demonstrated against different types of human cancer $[17,18]$. In addition, many studies have shown the antioxidant, anti-inflammatory, and anticancer potentials of microalgae species and their secondary metabolites, including carotenoids, fatty acids, glycolipids, and polysaccharides [19]. However, the physiological and molecular mechanisms underlying biological activities of the microalga-derived metabolites remain to be clearly elucidated.

The main purpose of this study was to assess the anti-inflammatory and cytotoxic effects of the ethanol extract from the polar microalga Micractinium sp. (ETMI) on the human colon cancer cell line, HCT116. In the present study, the anti-inflammatory activity of ETMI was determined by evaluating the expression patterns of inflammatory regulatory molecules, including IL-6, TNF-, COX-2, and iNOS, by using the well-characterized LPS-induced inflammation model in RAW 264.7 cells. The antiproliferative and cytotoxic effects of ETMI on the cancer cells were determined using two different assays, the 3-(4,5-dimethylthiazol2-yl)-5-(3-carboxymethoxyphenyl)-2-(4-sulfophenyl)2H-tetrazolium (MTT) and cell cycle assays, which showed a significant suppression of cellular proliferation and induction of cell cycle arrest in response to ETMI. These data suggest that ETMI may be a promising candidate as an anticancer agent for targeted therapy of colorectal cancer.

\section{Materials and Methods}

\section{Preparation of ETMI}

The microalga, Micractinium sp., was obtained from near King Sejong Station $\left(62^{\circ} 13^{\prime} \mathrm{S}, 58^{\circ} 47^{\prime} \mathrm{W}\right)$. To identify the microalga, its $18 \mathrm{~S}$ rDNA sequences were analyzed by Basic Local Alignment Search Tool (BLAST) for sequence similarities by using the NCBI GenBank database. A microalga sample was deposited at Korea Polar Research Institute, Republic of Korea (\# KSF105) (Fig. 1). ETMI was prepared as described previously [20].

\section{Cell culture}

RAW 264.7 macrophages and HCT116 cells were cultured in Dulbecco's modified Eagle's medium supplemented with $10 \%$ fetal bovine serum and $1 \%$ penicillin at $37^{\circ} \mathrm{C}$ in a humidified $\mathrm{CO}_{2}$ incubator. RAW 264.7 macrophages were incubated with or without different concentrations of ETMI for $1 \mathrm{~h}$ prior to LPS $(0.5 \mu \mathrm{g} / \mathrm{mL})$ stimulation. The HCT116 cells were seeded at a density of $5 \times 10^{3}$ cells/well in a 96-well plate and incubated in $5 \% \mathrm{CO}_{2}$ at $37^{\circ} \mathrm{C}$. 
A

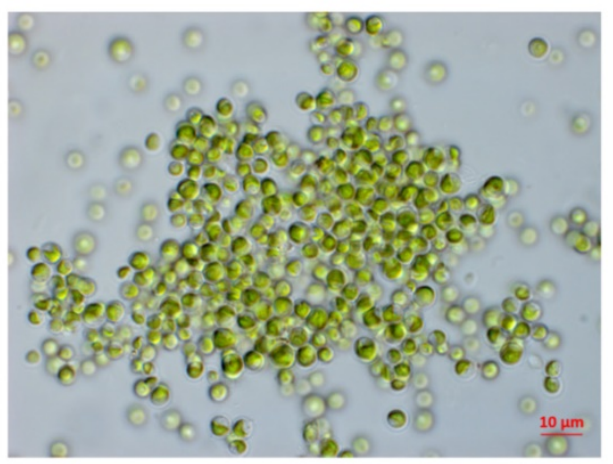

B

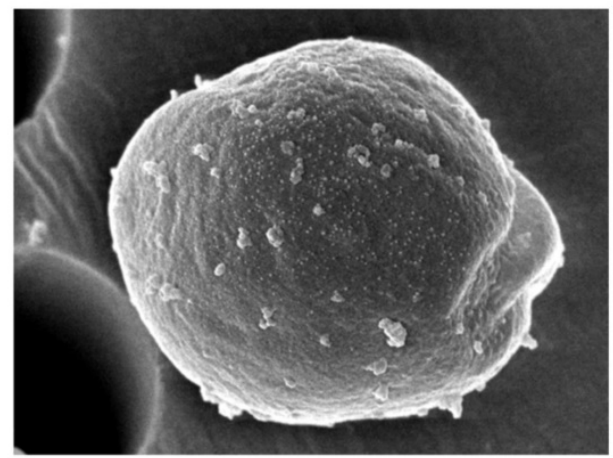

Figure 1. Morphological observation using light (A) and scanning electron microscopy (B)

\section{Measurement of NO production}

NO concentration in the RAW 264.7 cell culture supernatant was measured using Griess reagent. Briefly, $100 \mu \mathrm{L}$ of the supernatant was mixed with an equal amount of Griess reagent (1\% sulfanilamide in $5 \%$ phosphoric acid and $0.1 \% \mathrm{~N}$-(1-naphthyl) ethylenediamine). The mixture was incubated for $10 \mathrm{~min}$ at room temperature, and then the absorbance of each well was determined at a wavelength of $540 \mathrm{~nm}$ by using a microplate reader. Nitrite concentration was determined using a sodium nitrite calibration curve $(0-100 \mu \mathrm{M})$.

\section{Measurement of proinflammatory cytokine production}

RAW 264.7 macrophages were seeded at a density of $5 \times 10^{5}$ cells/well in 24-well plates and treated with various concentrations of $\operatorname{ETMI}(0,5,10$, 20 , and $40 \mu \mathrm{g} / \mathrm{mL}$ ) for $1 \mathrm{~h}$ and then stimulated with $0.5 \mu \mathrm{g} / \mathrm{mL}$ LPS for $24 \mathrm{~h}$. The cell culture media were collected and the levels of proinflammatory cytokines, TNF- $a$ and IL-6, were analyzed using enzyme-linked immunosorbent assay (ELISA) kits (Invitrogen, Carlsbad, CA, USA) according to the manufacturer's instructions.

\section{Cytotoxicity assay}

RAW 264.7 macrophages and HCT116 cells were seeded at a density of $1 \times 10^{5}$ cells/well in a 96-well plate. The macrophages were incubated with various concentrations of ETMI $(12.5,25$, and $50 \mu \mathrm{g} / \mathrm{mL})$ for 1 $\mathrm{h}$ and then stimulated with LPS $(1 \mu \mathrm{g} / \mathrm{mL})$ for $24 \mathrm{~h}$. Thereafter, cellular proliferation was analyzed by CellTiter 96AQucous One Solution Cell Proliferation Assay (Promega).

\section{Colony-forming assay}

HCT116 cells were seeded at a density of $\sim 1 \times 10^{3}$ in 6-well culture plates. To ensure cell adherence, the cells were incubated at $37^{\circ} \mathrm{C}$ for $24 \mathrm{~h}$ and then treated with various concentrations of ETMI (12.5, 25, 50, and $100 \mu \mathrm{g} / \mathrm{mL}$ ) for $12 \mathrm{~h}$. ETMI containing the culture medium was then removed; the cells were washed in phosphate-buffered saline (PBS) and incubated in regular medium until viable colonies were observed. The cells were then fixed with methanol-acetic acid (3:1), stained with the staining solution, and counted as described previously [20].

\section{RNA extraction and $q R T-P C R$}

To measure the mRNA expression of COX-2, IL-6, iNOS, and TNF-a, total RNA was isolated from ETMI-treated cells according to the manufacturer's instruction for TRIzol Reagent (Invitrogen). The first-strand copy DNA (cDNA) was synthesized using the Super Script first-strand cDNA synthesis kit (Invitrogen). Quantitative real-time polymerase chain reaction (qRT-PCR) was performed using SYBR green real-time PCR master mixes (ThermoFisher Inc., USA) with gene expression primers. Relative mRNA levels were normalized to those of the housekeeping gene $\beta$-actin. The primers used were as follows: iNOS: $(F)$ 5'-GGAGCCTTTAGACCTCAACAGA-3', (R) 5'-TGA ACGAGGAGGGTGGTG-3'; COX-2: (F) 5'-GAAGTCT TTGGTCTGGTGCGTG-3', (R) 5'-GTCTGCTGGTTTG GAATAGTTGC-3'; IL-6: (F) 5'-GAGGATACCACTC CCAACAGACC-3', (R) 5'-AAGTGCATCGTTGTTCA TACA-3'; TNF-a: (F) 5'-CATCTTCTCAAAATTCGAG TGACAA-3', (R) 5'-TGGGAGTAGACAAGGTACAA CCC-3'; $\beta$-actin: (F) 5'-TGTTTGAGACCTTCAACA CC-3', (R) 5'-CGCTCATTGCCGATAGTGAT-3'.

\section{Western blotting}

RAW 264.7 cells were seeded at a density of $5 \times$ $10^{5}$ cells $/ \mathrm{mL}$ in a 6-well plate. After overnight incubation, they were pretreated with different concentrations of ETMI for $1 \mathrm{~h}$ before the addition of LPS $(0.5 \mu \mathrm{g} / \mathrm{mL})$. After incubation for $24 \mathrm{~h}$, the cells were collected and lysed in radioimmunoprecipitation assay (RIPA) buffer. Western blotting was performed as previously described [19]. Anti-iNOS 
antibody was purchased from Sigma-Aldrich (Cat\# N7782), and anti-COX-2 and anti- $\beta$-actin antibodies were obtained from Cell Signaling (Cat\# 4842 and Cat\# 3700, respectively). Immunoblot signals were compared with those for $\beta$-actin and the relative protein expression was determined.

\section{Cell cycle analysis}

HCT116 cells were treated with various concentrations $(0,25,50$, and $100 \mu \mathrm{g} / \mathrm{mL})$ of ETMI and then incubated for $24 \mathrm{~h}$. The cells were then harvested and washed with PBS and fixed in 70\% ice-cold ethanol for at least $4 \mathrm{~h}$. Next, the cells were stained with a solution of PBS containing $50 \mathrm{~g} / \mathrm{mL}$ propidium iodide and $50 \mathrm{~g} / \mathrm{mL}$ RNase A. Cell cycle distribution was determined by flow cytometry (Becton Dickinson).

\section{Statistical analysis}

Values are presented as mean \pm SEM of three independent biological experiments. Statistically significant differences between each treated group and the control group were determined using
A

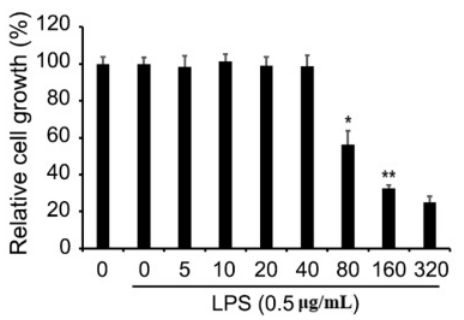

B

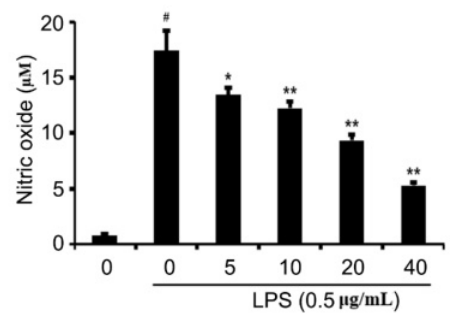

Figure 2. Effects of ETMI on cell viability and NO production in LPS-induced RAW 264.7 macrophages. After $24 \mathrm{~h}$ of treatment, cell viability was evaluated using an MTT assay (A) and NO production was determined by Griess reaction (B). The results are shown as mean \pm SD values of three experiments. ${ }^{*} p<0.05$, ${ }^{* *} p<0.01$, and $\# p<0.001$. ETMI: ethanol extract of Micractinium sp.; LPS: lipopolysaccharide; MTT: 3-(4,5-dimethylthiazol-2-yl)-5-(3-carboxymethoxyphenyl)-2-(4- sulfophenyl)-2H-tetrazolium; NO: nitric oxide

\section{A}
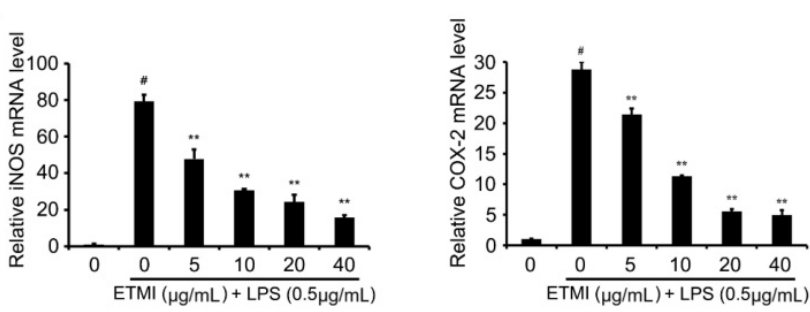

B
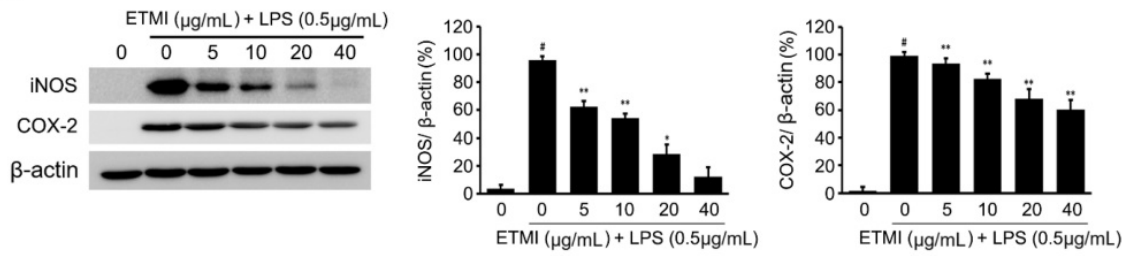

Figure 3. Effects of ETMI on the expression levels of proinflammatory mediators. The Transcriptional (A) and translational (B) levels of iNOS and COX-2 genes in response to ETMI treatment. Results are shown as mean \pm SD values of three experiments; ${ }^{*} p<0.05$, ${ }^{*} p<<0.01$, and $\# p<0.001$. ETMI: ethanol extract of Micractinium sp.; iNOS: inducible nitric oxide synthase; COX: cyclooxygenase one-way analysis of variance followed by Student's $t$-test; $\mathrm{p}$ values $<0.05$ were considered to indicate a statistically significant difference.

\section{Results}

\section{Effect of ETMI on RAW 264.7 cell viability}

To determine the cytotoxicity of ETMI in RAW 264.7 cells, the cells were exposed to various concentrations of ETMI, from $5 \mu \mathrm{g} / \mathrm{mL}$ to $320 \mu \mathrm{g} / \mathrm{mL}$, and then treated with $1 \mu \mathrm{g} / \mathrm{mL}$ LPS for $24 \mathrm{~h}$. Thereafter, the cell growth rate was determined using of RAW 2647 cells was not significantly affected by treatment with ETMI at concentrations up to 40 $\mu \mathrm{g} / \mathrm{mL}$ compared to that of the cells without LPS or ETMI treatment.

\section{Effects of ETMI on LPS-induced NO}

To determine the inhibitory effect of ETMI on the LPS-induced proinflammatory reaction, the expression levels of the main proinflammatory mediators, iNOS and COX-2 genes, in ETMI-treated RAW 264.7 cells were determined. The cells exposed to ETMI at concentrations of 5, 10, 30, and 40 $\mu \mathrm{g} / \mathrm{mL}$ for $1 \mathrm{~h}$ did not show a cytotoxic effect; thereafter, the cells were treated with $1 \mu \mathrm{g} / \mathrm{mL}$ LPS for $24 \mathrm{~h}$. As shown in Fig. 2B and 3, LPS-stimulated expression of both iNOS and COX-2 significantly reduced in a dose-dependent manner at both the transcriptional (Fig. 2B) and translational levels (Fig. 3) compared to that in the control cells, which received only LPS stimulation and not ETMI pretreatment. Next, the level of $\mathrm{NO}$, which is one of the principal mediators of inflammation, was determined using Griess reagent under the same condition. We found that ETMI markedly decreased LPS-stimulated NO production in a dose-dependent manner (Fig. 2C). Taken together, these findings suggest that ETMI has high anti-inflammatory activity even at low concentrations through the modulation of the main regulators of inflammation at both the transcriptional and translational levels. 


\section{Effects of ETMI on LPS-stimulated} proinflammatory cytokine production

Many proinflammatory cytokines including TNF- $\alpha$ and IL-6 can be important regulators of inflammatory processes and diseases [15, 16]. To evaluate the effect of ETMI on the expression patterns of proinflammatory cytokine genes, RAW 264.7 macrophages were treated with different concentrations of ETMI from 5 to $40 \mu \mathrm{g} / \mathrm{mL}$ for $1 \mathrm{~h}$ and then stimulated with $1 \mathrm{mg} / \mathrm{mL}$ LPS for $24 \mathrm{~h}$. We found that the LPS-induced expression of TNF- $\alpha$ and IL-6 significantly decreased in the ETMI-treated cells in a concentration-dependent manner compared to that in the untreated cells with or without LPS stimulation (Fig. 4). Next, we investigated the effect of ETMI on the production of cytokines in RAW 264.7 macrophages by detecting TNF-a and IL-6 using ELISA. As shown in Fig. 4, ETMI, at a concentration of $40 \mu \mathrm{g} / \mathrm{mL}$, significantly decreased the LPS-mediated increase in the level of IL-6 in RAW 264.7 cells by approximately 5 -fold over that in the controls, while the LPS-stimulated TNF- $\alpha$ production slightly decreased in a dose-dependent manner despite a significant decrease in its mRNA level. These data suggest that ETMI may be a promising regulator of inflammatory processes through the regulation of proinflammatory cytokine production.

\section{Cytotoxic effect of ETMI on HCT 116 cells}

Chronic inflammation has been reported to cause cancer through the modulation of oncogenic signaling pathways [21]. We wondered whether ETMI can inhibit tumorigenesis by exerting anti-inflamm-
A

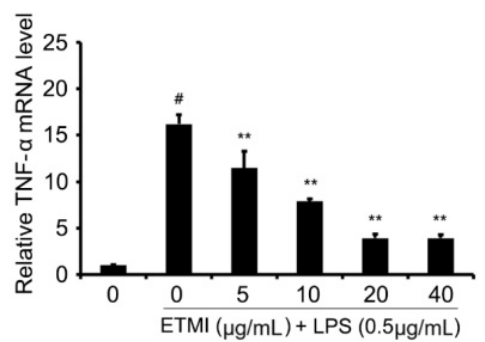

B

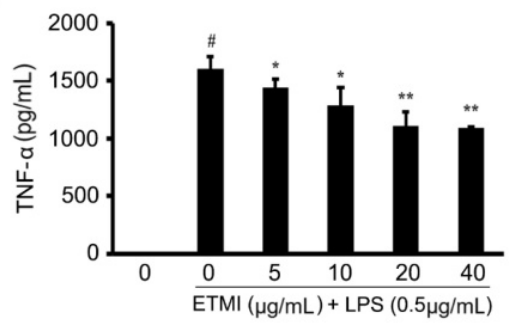

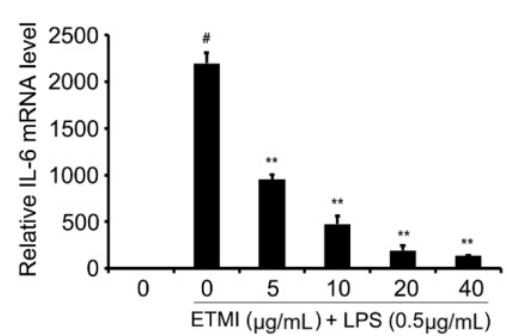

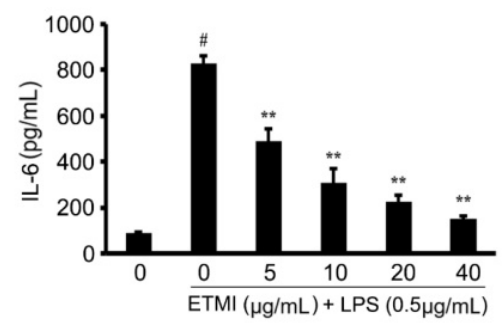

Figure 4. Effects of ETMI on the expression and production of proinflammatory cytokines. Transcriptional levels (A) and production (B) of cytokines, TNF- $\alpha$ and IL-6. Results are shown as mean $\pm S D$ values of three experiments. $*_{p}<0.05$, $*_{p}<0.01$, and $\# p<0.001$. ETMI: ethanol extract of Micractinium sp.; TNF: tumor necrosis factor; IL: interleukin atory activity. To evaluate the growth-inhibitory effect of ETMI on HCT116 cells, a colorimetric MTS assay was performed. HCT116 cells were treated with various concentrations of ETMI $(0,12.5,25,50$, and $100 \mu \mathrm{g} / \mathrm{mL}$ ) for $24 \mathrm{~h}$. As shown in Fig. 5A, at concentrations of $\geq 25 \mu \mathrm{g} / \mathrm{mL}$, ETMI suppressed the proliferation of the HCT116 cells in a concentrationdependent manner, suggesting that ETMI exhibits concentration-dependent inhibitory activity against HCT116 cells. Furthermore, the conclusion was supported by the colony formation of ETMI-treated cancer cells: the number of ETMI-treated cell colonies decreased compared to those of the control cells (Fig. 5B).

\section{Induction of cell cycle arrest in the ETMI-treated HCT 116 cells}

To further understand the potential mechanisms by which ETMI exhibits its inhibitory activity, the effect of the extract on cell cycle distribution in HCT116 cells was investigated using a flow cytometry assay. As shown in Fig. 6, the cell population in the G0/G1 phase significantly increased in a dosedependent manner, while that in the $S$ phase decreased. Of the control cells, $38.61 \%$ were in the G0/G1 phase, $36.93 \%$ were in the S phase, and $24.45 \%$ were in the G2/M phase. However, the percentage of extract-treated cells in the G1 phase (38.61\%) gradually increased with an increase in the concentrations of the extract up to $100 \mu \mathrm{g} / \mathrm{mL}$ (38.61\% at $0 \mu \mathrm{g} / \mathrm{mL}, 43.83 \%$ at $25 \mu \mathrm{g} / \mathrm{mL}, 46.77 \%$ at 50 $\mu \mathrm{g} / \mathrm{mL}$, and $51.83 \%$ at $100 \mu \mathrm{g} / \mathrm{mL}$ ). The cell population in the $\mathrm{S}$ phase decreased at the same concentrations $(36.94 \%$ at $0 \mu \mathrm{g} / \mathrm{mL}$, $37.32 \%$ at $25 \mu \mathrm{g} / \mathrm{mL}, 31.47 \%$ at 50 $\mu \mathrm{g} / \mathrm{mL}$ and $27.16 \mu \mathrm{g} / \mathrm{mL}$ ) (Fig. 6A). These data provide strong evidence of cell cycle arrest at the G1 phase, and in turn, the inhibition of HCT116 cell division by ETMI. To further investigate the effect on cell cycle distribution, the transcriptional levels of marker proteins of G1 phase transition were analyzed by qRT-PCR. The results (Fig. 6B) indicated that ETMI treatment led to significantly increased levels of p21 mRNAs in a concentration-dependent manner, whereas the expression of CDK4 and CDK6 mRNAs decreased. These data suggest that ETMI suppressed proliferation, at least in part, by modulating the expression levels of regulatory genes in the G1/S transition phase. 
A

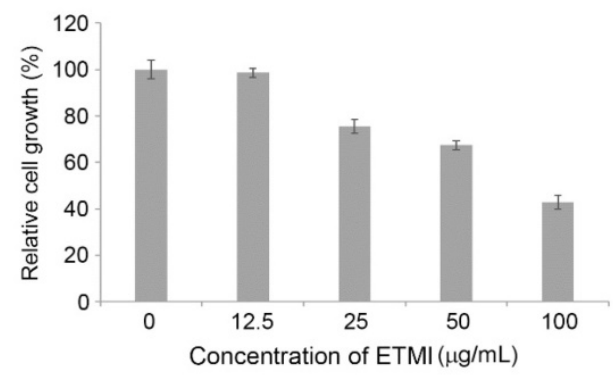

B

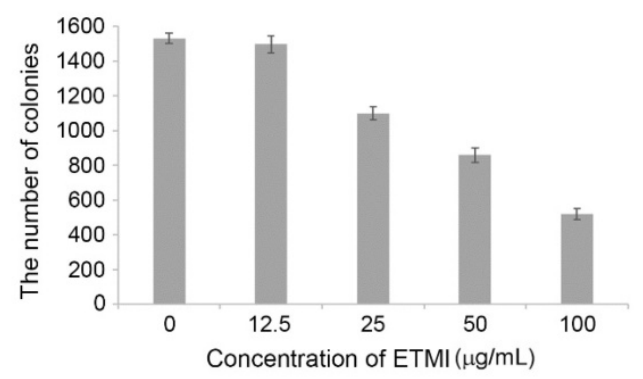

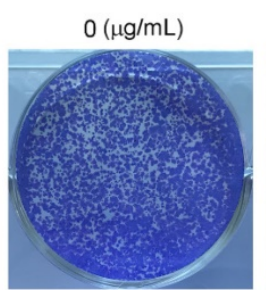

$12.5(\mu \mathrm{g} / \mathrm{mL})$
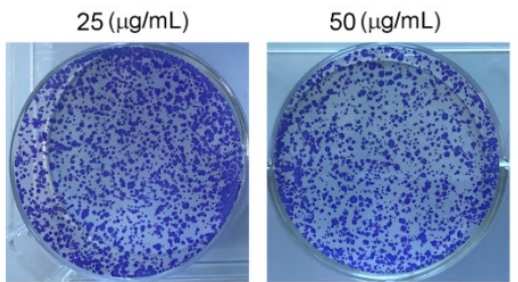

$100(\mu \mathrm{g} / \mathrm{mL})$

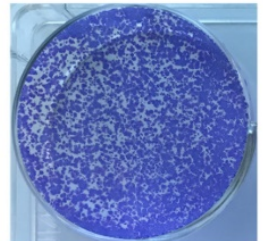

Figure 5. Effects of ETMI on the growth of human colon cancer cells, HCT116. Inhibition of cell proliferation (A) and colony formation (B) in response to ETMI treatment. ETMI: ethanol extract of Micractinium sp.

A
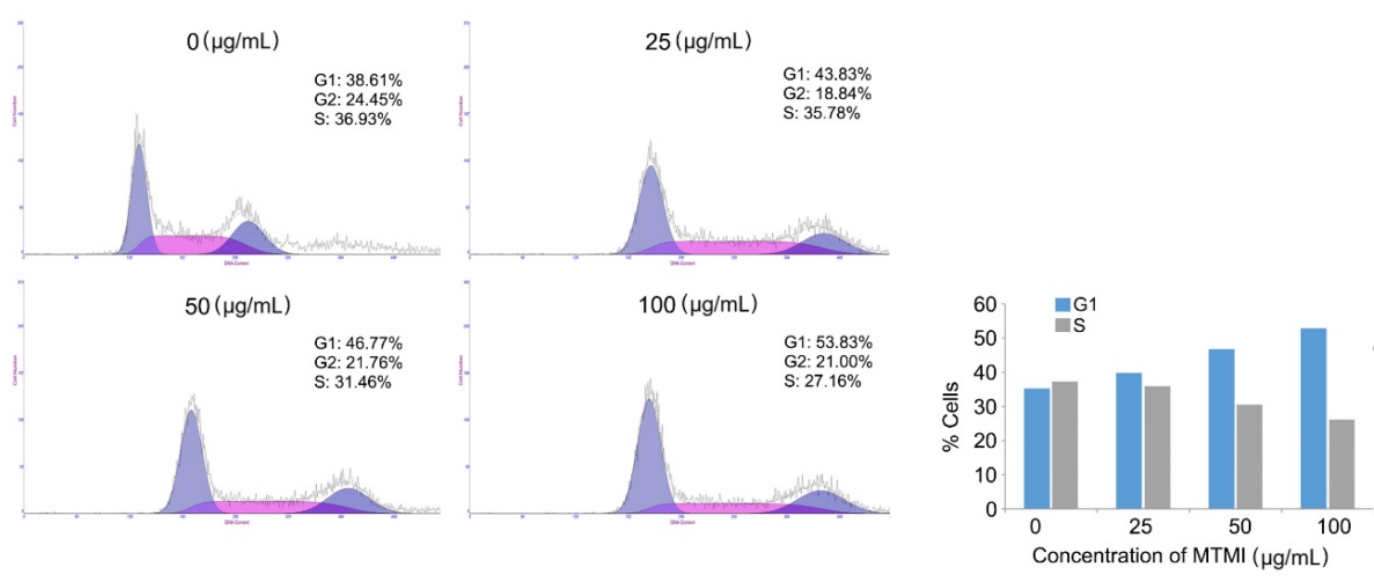

B
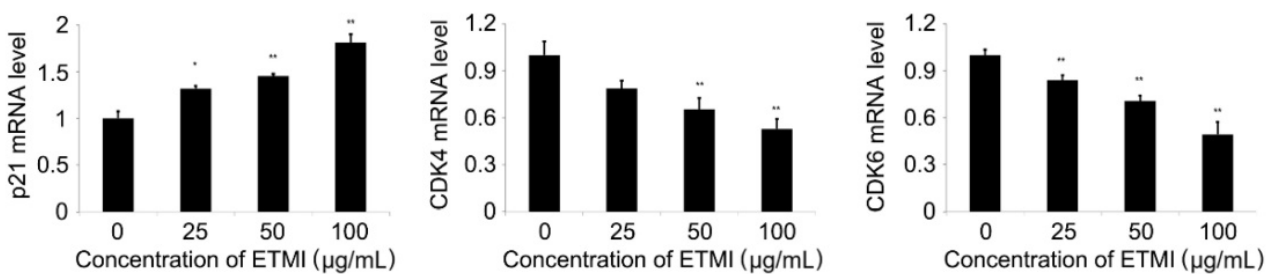

Figure 6. Induction of cell cycle arrest (A) and expression pattern of the cell cycle-regulated genes in response to ETMI treatment (B). Results are shown as mean $\pm S D$ values of three experiments. ${ }^{*} p<0.05$, ${ }^{*} p<<0.01$. ETMI: ethanol extract of Micractinium sp.

\section{Discussion}

It is known that chronic inflammation causes various diseases including cancer [22]. Therefore, if the inflammatory reaction is not controlled early, it can develop into a chronic infection, an autoimmune disease, or a metabolic disease, due to loss of function and disruption of homeostasis in the body. Recent studies that investigated whether chronic inflammation increases cancer incidence have shown that inflammation and cancer have a common signaling pathway involving a vicious cycle linkage at the molecular level [23, 24]. Inflammatory substances secreted by inflammatory cells are closely related to the proliferation, survival, and metastasis of cancer cells. In the inflammatory tumor microenvironment, inflammation not only promotes the survival and proliferation of cancer cells but also induces angiogenesis and metastasis by destroying the 
adaptive immune response and altering the response to hormones and drugs. For example, when acute inflammation is not resolved and progresses to chronic inflammation, inflammatory cells are broken down and TNF-a, IL-1, and IL-6 cause DNA damage or mutagenesis. Inflammatory cells overexpress inflammatory cytokines or enzymes such as EGF, MMP, and MCP [12-15]. In addition, in the inflammatory tumor microenvironment, hypoxiainduced factor produces vascular endothelial growth factor (VEGF) [25]. These substances can change the inflammatory microenvironment around the tumor and help the tumor to proliferate and induce metastasis by making it easier for the tumor cells to break down nearby tissues and spread to other organs. In the present study, we demonstrated that ETMI exhibited anti-inflammatory and anticancer activities, using several in vitro assays in RAW 264.7 macrophages and HCT116 cells. Based on our data, ETMI exerts anti-inflammatory effects by modulating the expression levels of inflammatory regulators such as COX-2, IL-6, iNOS, and TNF-a, and the production of inflammation-stimulated $\mathrm{NO}$ and proinflammatory cytokines such as IL-6 and TNF-a. In particular, anti-inflammatory activity was observed at a relatively low concentration $(5 \mu \mathrm{g} / \mathrm{mL})$ of ETMI, indicating a decrease in the expression levels of inflammatory mediators compared to those reported previously [26, 27]. ETMI may include bioactive molecules with strong anti-inflammatory activities, which are necessary for adaptation in harsh conditions such as those in the Antarctic region. In general, to adapt to extreme environments such as those in the Antarctic region, organisms including microalgae have developed specific self-defense mechanisms by synthesizing toxic secondary metabolites, which have been found to be pharmaceutically useful. In this aspect, bioactive compounds from Antarctic organisms may be promising pharmaceutical targets for developing new drugs. Based on our data on inflammatory molecular mechanisms, ETMI effectively regulated the transcription level of proinflammatory mediators. However, whereas both transcription levels and the production of proinflammatory cytokine IL-6 were significantly inhibited by ETMI treatment, TNF- $\alpha$ production slightly reduced in a dose-dependent manner compared to the marked reduction in its mRNA levels. This regulatory discrepancy between TNF- $\alpha$ mRNA and production may occur because the rapid turnover of TNF- $\alpha$ mRNA does not have a large effect on TNF-a biosynthesis in macrophages. In fact, it has been reported that TNF- $\alpha$ mRNA is short-lived even in conditions of maximal TNF- $\alpha$ production during tumor necrosis, suggesting that TNF-a mRNA rapid turnover is not involved in the regulatory mechanism of TNF-a biosynthesis [28]. On the other hand, ETMI exerts anticancer activity to inhibit proliferation of human colon cancer cells by arresting the cell cycle. In particular, ETMI induced G1 phase arrest in a dose-dependent manner by modulating the expression level of G1/S regulators such as CDKN1A, $C D K 4$, and $C D K 6$. This result suggests that some bioactive molecules in ETMI play an important role in the tight regulation of G1/S phase transition.

In the present study, we demonstrated that ethanol extract from Antarctic freshwater microalga, Micractinium sp., has anti-inflammatory and anticancer activities against macrophages and colon cancer cells, respectively. Recently, to better understand the regulatory mechanism associated with the inflammation-to-cancer transition, investigation of the specific roles of the main regulatory molecules involved in this process has been emphasized. The identification of bioactive compounds that mediate the common signaling pathway between inflammation and cancer and the development of drugs that interfere with the function of these proteins may be an effective approach for treating cancer by eliminating the link between inflammation and cancer. Taken together, our results indicate that ETMI may be a promising candidate for the development of a pharmaceutically effective drug for cancer therapy.

\section{Acknowledgement}

This research was supported by the research projects (PE17180) of Korea Polar Research Institute, Republic of Korea.

\section{Competing Interests}

The authors have declared that no competing interest exists.

\section{References}

1. Petersen HJ, Smith AM. The role of the innate immune system in granulomatous disorders. Front Immunol. 2013; 4: 120.

2. Chovatiya R, Medzhitov R. Stress, inflammation, and defense of homeostasis. Mol Cell. 2014; 54: 281-288.

3. Garrett WS, Gordon JI, Glimcher LH. Homeostasis and inflammation in the intestine. Cell.2010; 140: 859-870.

4. Cekici A, Kantarci A, Hasturk H, Van Dyke TE. Inflammatory and immune pathways in the pathogenesis of periodontal disease. Periodontol. 2000; 64: 57-80.

5. Chaplin DD. Overview of the immune response. J Allergy Clin Immunol. 2010; 125: S3-23.

6. Arango Dugue G, Descoteaux A. Macrophage cytokines: involvement in immunity and infectious diseases. Front Immunol. 2014; 5: 491.

7. Turner MD, Nedjai B, Hurst T, Pennington DJ. Cytokines and chemokines: at the crossroads of cell signaling and inflammatory disease. Biochim Biophys Acta. 2014; 1843: 2563-2582.

8. Hunter P. The inflammation theory of disease. EMBO Rep. 2012; 13: 968-970.

9. Hasturk H, Kantarci A, Van Dyke TE. Oral inflammatory diseases and systemic inflammation: role of the macrophage. Front Immunol. 2012; 3:118.

10. Godkin A, Smith KA. Chronic infections with viruses or parasites: breaking bad to make good. Immunology. 2017; 150: 389-396. 
11. Mostofa AG, Punganuru SR, Madala HR, Al-Obaide M, Srivenugopal KS. The process and regulatory components of inflammation in brain oncogenesis. Biomolecules. 2017; 7: E34.

12. Kim JB, Han AR, Park EY, Kim JY, Cho W, Lee J, et al. Inhibition of LPS-induced iNOS, COX-2 and cytokines expression by poncirin through the NF-kappaB inactivation in RAW 264.7 macrophage cells. Biol Pharm Bull. 2007; 30: 2345-2351.

13. Chun KS, Cha HH, Shin JW, Na HK, Park KK, Chung WY, et al. Nitric oxide induces expression of cyclooxygenase-2 in mouse skin through activation of NF-kappaB. Carcinogenesis. 2004; 25: 445-454.

14. Lawrence T. The nuclear factor NF-kB pathway in inflammation. Cold Spring Harb Perspect Biol. 2009; 1: a001651.

15. Shukla S, Shankar E, Fu P, MacLennan GT, Gupta S. Suppression of NF-kB and NF-KB-regulated gene expression by apigenin through IкB $\alpha$ and IKK pathway in TRAMP mice. PLoS One. 2015; 10: e0138710.

16. Rinkenbaugh AL, Baldwin AS. The NF-KB pathway and cancer stem cells. Cells. 2016; 5: E16

17. Suh SS, Kim TK, Kim JE, Hong JM, Nguyen TTT, Han SJ, et al. Anticancer activity of ramalin, a secondary metabolite from the Antarctic lichen Ramalina Terebrata, against colorectal cancer cells. Molecules. 2017; 22: E1361.

18. Hong JM, Suh SS, Kim TK, Kim JE, Han SJ, Youn UJ, et al. Anti-cancer activity of lobaric acid and lobarstin extracted from the Antarctic lichen Stereocaulon alpnum. Molecules. 2018; 23: E658.

19. Talero E, García-Mauriño S, Ávila-Román J, Rodríguez-Luna A, Alcaide A, Motilva V. Bioactive compounds isolated from microalgae in chronic inflammation and cancer. Mar Drugs. 2015; 13: 6152-6209.

20. Suh SS, Yang EJ, Lee SG, Youn UJ, Han SJ, Kim IC, et al. Bioactivities of ethanol extract from the Antarctic freshwater microalga, Chloromonas sp. Int J Med Sci. 2017; 14: 560-569.

21. Multhoff G, Molls M, Radons J. Chronic inflammation in cancer development. Front Immunol. 2011; 2: 98

22. Grivennikov SI, Greten FR, Karin M. Immunity, inflammation, and cancer. Cell. 2010; 140: 883-899.

23. Vlodavsky I, Beckhove P, Lerner I, Pisano C, Meirovitz A, Ilan N et al. Significance of heparanase in cancer and inflammation. Cancer Microenviron. 2012; 5: 115-132.

24. Zhang Q, Zhu B, Yongsheng L. Resolution of cancer-promoting inflammation: a new approach for anticancer therapy. Front Immunol. 2017; 8: 71.

25. Finger EC, Giaccia AJ. Hypoxia, inflammation, and the tumor microenvironment in metastatic disease. Cancer Metastasis Rev. 2010; 29: 285-293.

26. Samarakoon KW, Ko JY, Shah MR, Lee JH, Kang MC, Nam ON et al. In vitro studies of anti-inflammatory and anticancer activities of organic solvent extracts from cultured marine microalgae. Algae. 2013; 28: 111-119.

27. Sanjeewa KKA, Fernando IPS, Samarakoon KW, Lakmal HHCL, Kim EA, Kwon $\mathrm{ON}$ et al. Anti-inflammatory and anti-cancer activities of sterol rich fraction of cultured marine microalga Nannochloropsis oculata. Algae. 2016; 31: 277-287.

28. Mijatovic T, Houzet L, Defrance P, Droogmans L, Huez G, Kruys V. Tumor necrosis factor-alpha mRNA remains unstable and hypoadenylated upon stimulation of macrophages by lipopolysaccharides. Eur J Biochem. 2000; 267: 6004-6012. 